\title{
EI constitucionalismo mexicano en la era de los Millennials
}

\author{
Gabriela Valles Santillán* \\ Recibido: 10 de Mayo \\ Dictaminado: 26 de Julio
}

\begin{abstract}
Resumen
En esencia, este trabajo aborda de manera breve el siguiente cuestionamiento: ¿El constitucionalismo mexicano resulta acorde a los ideales de vida de las generaciones actuales, entre éstas, la de los Millennials? O en todo caso, ¿los satisface a plenitud? El trabajo va dirigido concretamente a destacar las necesidades sociales cotidianas e ideales de los mexicanos Millennials, en contraste con aquellos rasgos sociológicos propios de las generaciones previas, las cuales definieron el constitucionalismo mexicano desarrollado sustancialmente durante el siglo XX.

Palabras clave: Constitucionalismo, Derechos, Interpretación, Mexicanos, Millennials, Derechos.
\end{abstract}

\section{Mexican constitutionalism in the Millennials Era}

\begin{abstract}
Mainly, this work addresses briefly the following questioning: Does Mexican constitutionalism fit the life ideals of the current generations, and among them, the so called Millennials? Or, in any case, even fully satisfy those ideals? The goal of this paper is to highlight the Mexican Millenials's ideals and social needs, in contrast to those sociological features typical of previous generations, which defined the Mexican constitutionalism developed substantially during the twentieth century.

Key words: Constitutionalism, Interpretation, Mexicans, Millennials, Rights.
\end{abstract}

\footnotetext{
* Investigadora de la Facultad de Derecho y Ciencias Políticas de la Universidad Juárez del Estado de Durango (México).divalles60@hotmail.com
} 


\section{Sumario}

I Introducción; II Rasgos sociológicos de los mexicanos durante el siglo XX; III Líneas programáticas de corte social contempladas en el constitucionalismo mexicano del siglo XX; IV Los Millennials mexicanos en el siglo XXI. ¿Decadencia del constitucionalismo programático de post revolución?; V El surgimiento de nuevas perspectivas de justicia constitucional como avance significativo del constitucionalismo mexicano en la era de los Millennials; VI Conclusiones; Bibliografía.

\section{Introducción}

La vida cotidiana del mexicano Millennial, a diferencia de las circunstancias reales en las que vivieron las generaciones pasadas, se encuentra supeditada a avances científicos y tecnológicos que han transformado el mundo en los últimos treinta años (por ejemplo, el surgimiento del internet, y con ello, la evolución de los medios para transmitir la información, y la consecuencia de establecer los mecanismos para proteger el derecho a la misma).

Tales avances, sin lugar a duda, infieren en el constitucionalismo mexicano contemporáneo, y en concreto, en el contenido sustancial del ordenamiento supremo vigente.

Ahora bien, en primer lugar, ¿a qué nos referimos con el término constitucionalismo, en un contexto en el que se da énfasis a un Estado Constitucional y Democrático de Derecho?

En palabras de Sáchica (2002:3), el constitucionalismo surge “(...) cuando un pueblo (...) asume la responsabilidad de hacer su propia historia, cuando deja de ser pasivo y se convierte en protagonista, en autor de su vida colectiva (...)". Tal aseveración se construye desde una perspectiva de tipo material. Por otro lado, el término constitucionalismo también puede referirse, empleando una óptica formal, como aquél proceso de construcción normativa en el que quedan configurados los pactos sociales y políticos sobre la base de dos elementos fundamentales: la estructura estatal y el reconocimiento de los derechos individuales (López Guerra y otros, 2013:35). 
En lo que concierne a la evolución formal del constitucionalismo mexicano, en un contexto estadual democrático-moderno, se destaca lo siguiente:

Históricamente, la Constitución de 1917 superó el liberalismo individualista y abstencionista característico del siglo XIX, en tanto que, diseñada sobre una base sólida de contenido ético deontológico, pugnó por la igualdad en el goce de los derechos de libertad y de propiedad.

Estos derechos, si bien de alguna manera ya se habían contenido al amparo de la Constitución de 1857, lo cierto es, que fueron retomados por los constituyentes de 1916, al considerar que aún faltaban algunos detalles por perfilar en el diseño institucional del Estado Mexicano, para conseguir un modelo jurídico-político con una visión netamente social o de interés general.

En ese orden cronológico se fue desarrollando el constitucionalismo mexicano en el plano pragmático del discurso, alcanzando un nivel de clímax sustancial con líneas programáticas de corte social hacia principios del siglo XX -concretamente, cuando es emitida la Constitución de 1917-, dando paso al siglo XXI conservando la vigencia de dicho documento jurídico supremo.

En tales líneas programáticas se destaca la inclusión de tópicos como: el derecho a la educación primaria laica, gratuita y obligatoria; el derecho de las personas a desempeñar una profesión, comercio o trabajo que mejor se acomodase a sus condiciones particulares; y la libre manifestación de ideas, entre otros derechos de gran impacto social (Covarrubias, 2009: 577 - 627).

Ahora bien, hoy en día, a cien años de la promulgación de la Carta Magna de 1917 -parteaguas del constitucionalismo mexicano del siglo XX- cabe preguntarse en qué medida el contenido sustancial de dicho ordenamiento supremo se encuentra a la par del desarrollo de los avances tecnológicos y las nuevas tendencias del mundo globalizado que dan sentido al entorno social de la llamada generación Millennials.

Ello, en el entendido de que los Millennials mexicanos requieren la existencia de un marco constitucional y legal que dé respuesta a tópicos de su interés, como lo son -siguiendo las palabras del historiador Enrique Krauze (2016)-: la familia (respecto de la cual, no todos coinciden en que sea reconocido únicamente el modelo tradicional); la paternidad (de igual forma, no todos la conciben desde una perspectiva tradicionalista); la diversidad sexual 
(tan polémica en la actualidad); nuevas modalidades de trabajo y captación de ingresos; regulación de redes innovadoras de pago y contratación (como la nueva moneda del ciberespacio llamada bitcoin); la equidad de género; la amistad; la literatura, la música y el cine; la protección de los animales; el medio ambiente; la difusión de la información a través de redes sociales y otros instrumentos tecnológicos; la protección de la información y datos personales a través de soluciones tecnológicas de encriptamiento; la bioética, entre otros.

Lo anterior, tomando por supuesto en consideración el hecho de que, si algo de esto es cierto (Krauze, 2016), es que lo que sí repudian los Millennials mexicanos es el tema relacionado con la política mexicana (y los entes de interés público que participan en ésta), factor determinante para la continua adecuación del marco normativo al contexto social.

En mérito de lo ya señalado, y con el ánimo de verificar si existe o no decadencia del constitucionalismo contemporáneo en México, en lo tocante a una posible discrepancia entre el marco jurídico y la realidad social en la que se desenvuelven los individuos de actualidad, a continuación se exponen -de manera breve- rasgos sociológicos característicos de la población mexicana que vivió en los primeros años del siglo XX, y subsecuentes hasta 1980 aproximadamente, para luego señalar algunas de las condiciones sociales que quedaron predispuestas a las generaciones siguientes (a partir de 1980 y hasta 1995, se suele ubicar a la generación de los Millennials).

El contraste de tales rasgos sociológicos entre grupos de individuos tiene como finalidad responder de una manera directa -aunque breve, ya que un desarrollo concienzudo daría lugar a un trabajo de investigación de mayor extensión motivo de una publicación diversa- a la simple interrogante relativa a si el constitucionalismo mexicano resulta acorde a los ideales de vida de las generaciones actuales, entre éstas, la de los Millennials. Dicha interrogante fue planteada en el resumen de este trabajo de investigación, con el ánimo de dejar en claro el objetivo primordial de la misma.

Finalmente, este trabajo presentará de manera sintética el tópico concerniente al surgimiento de nuevas perspectivas de justicia constitucional como un ejemplo de avance significativo del constitucionalismo mexicano en la era de los Millennials. 


\section{Rasgos sociológicos de los mexicanos durante el siglo XX}

En este apartado, cabe distinguir una serie de categorías: las condiciones y rasgos sociológicos que caracterizaron a los mexicanos que vivieron a principios del siglo XX; las condiciones y rasgos propios de aquella población -comprendida en la también llamada generación $X^{1}$ - activa en el país a partir de mediados de ese siglo; y por último, las condiciones y rasgos sociológicos en los que se desarrolla actualmente la generación de los mexicanos Millennials, comprendida por los nacidos entre 1980 a 1995, aproximadamente.

Por su parte, Enrique Krauze (2016) distingue las siguientes generaciones mexicanas en la actualidad:

"En el escenario político mexicano hay tres generaciones actuantes: la Generación de la discordia (1950-1965), la Generación mediática (19651980) y los Millennials. La primera deberá resolver su querella en 2018. La segunda debería encabezar una cultura del debate público y evitar que naufrague la democracia que, con todos sus defectos, costó tanto alcanzar”.

Una vez que ha sido precisado lo anterior, a continuación se detallarán en sub apartados, las condiciones y rasgos sociológicos más sobresalientes de cada una de las generaciones señaladas.

a) Mexicanos de principios del siglo $\mathrm{XX}$, en un periodo comprendido hasta 1968 aproximadamente (algunos, partícipes en la Revolución Mexicana; otros, hijos de los revolucionarios que continuaron su legado):

Se consultaron diferentes fuentes bibliográficas para el desarrollo de éste y

\footnotetext{
1 Personas cuyos nacimientos, generalmente y de manera aproximada, se ubican entre 1961 hasta 1981, según los datos obtenidos en la versión electrónica de la Revista Muy Interesante, cuya referencia bibliográfica es: SANZ, E. (2014). ¿Cómo son los miembros de la Generación X? Revista Muy Interesante. Recuperado el 5 de noviembre, 2016, de: http://www.muyinteresante.es/salud/articulo/icomo-son-los-miembros-de-lageneracion- $\mathrm{X}$
} 
los posteriores sub apartados.

Según la información obtenida del estudio realizado en la obra denominada Cambio demográfico y social en el México del siglo XX. Una perspectiva de historias de vida, en cuya edición participaron diversas instituciones académicas de alto reconocimiento, así como la propia Cámara de Diputados del Congreso de la Unión (LIX Legislatura), y en la que se expusieron los resultados emanados de la Encuesta Demográfica Retrospectiva (Eder), con la colaboración el Instituto Nacional de Estadística, Geografía e Informática (INEGI), para lograr extraer los rasgos sociológicos de los mexicanos de principios del siglo XX, estos últimos fueron agrupados en lo que podríamos identificar como diversas secciones llamadas cohortes ${ }^{2}$ obtenidas de determinadas muestras estadísticas representativas, estableciéndose inicialmente “(...) cuatro cohortes (1905-1914, 1915-1924, 1925-1934, 1935-1944) (...)" para estudiar variaciones sociológicas en el tiempo; luego, se formaron otras tres cohortes de nacimiento sujetas a análisis “(...) (1936-1938, 1951-1953, 1966-1968) (...)” (Browning, 2004: 8), mismas que arrojaron rasgos que serán detallados en el siguiente sub apartado de esta investigación.

En ese orden de ideas, de acuerdo a la fuente que se presenta en primer término, un análisis profundo de la sociedad mexicana durante diversos periodos del siglo XX, obedece a “(...) capturar los procesos de cambio que dieron pie a una nueva estratificación social en el país, impulsado principalmente por una acelerada industrialización, la transformación económica y sociopolítica del campo mexicano, la migración masiva rural-urbana, la expansión del sistema educativo mexicano, la caída acelerada de la mortalidad, entre otros condicionantes (...)" (Coubès, 2004: 11-12); todas éstas variaciones originadas durante la pasada centuria, han incidido de manera definitiva en los ideales y modos de vida de la generación actual de mexicanos en el siglo XXI.

\footnotetext{
2 Según el Diccionario de la Real Academia Española, el término se refiere a "conjunto, número, serie" (disponible en http://dle.rae.es/?id=9hNlUuG); mientras que en el ámbito concreto de la Estadística, los llamados estudios de cohorte "se han utilizado de manera clásica para determinar la ocurrencia de un evento específico en un grupo de individuos (...)", según la fuente bibliográfica: Lazcano-Ponce, E. y otros (2000). Estudios de cohorte. Metodología, sesgos y aplicación. Revista Salud Pública de México, Volumen 42 (edición del Instituto Nacional de Salud Pública, Número 3, mayo-junio de 2000). Recuperado el 7 de noviembre, 2016, de: $\underline{\text { http://www.scielosp.org/scielo.php?script=sci arttext\&pid=S0036-36342000000300010 }}$
} 
Ahora bien, conforme al estudio que se narra, a continuación se enlistan condiciones y rasgos peculiares de la sociedad mexicana de principios del siglo XX (Coubès y otros, 2004) $)^{3}$ :

La mayoría de los niños no acuden a la escuela. Si bien para 1921 se creó la Secretaría de Educación Pública, y uno de sus propósitos era expandir la educación básica primaria para lograr un avance en la integración social, y aunque para los años treinta, se dio en el país una ideología socialista implantada por el gobierno para ofrecer mayores oportunidades a los hijos de los trabajadores rurales y obreros (Latapí citado por Mier y otro, 2004:11-12), lo cierto es, que la deserción escolar era alta y el nivel educativo era escaso, sobretodo en la zona rural.

Para este periodo, la principal fuente de trabajo es la tierra. Luego de consolidarse los lemas revolucionarios agraristas, el reparto de tierras incrementó considerablemente, sobretodo en la década de los años treinta. Debido a esta circunstancia, la mayor parte de la infancia de los mexicanos de aquellos tiempos, transcurría en los hogares y en el campo (donde aprendían de sus padres oficios manuales no calificados, observándose, por lo tanto, una mínima diferencia ocupacional en el sector rural, de los hijos frente a los padres).

Se observa que hubo estabilidad matrimonial en los mexicanos casados (hay una prevalencia de matrimonios religiosos y civiles), con riesgos mínimos de ruptura por separación; aunque, durante los primeros años del siglo XX en México, las mujeres se encontraban expuestas a riesgos de disolución matrimonial por causa de situación de viudez, debido precisamente a las consecuencias de la inestabilidad social de pos-guerra revolucionaria (muertes en combate).

A partir de la segunda mitad de la década de los cincuenta, se advierte un descenso en la mortalidad de mexicanos; y una fecundidad elevada a partir de ese periodo, con índices de nupcialidad precoz. Ello, debido a la estabilidad conseguida para esos años, con buenas condiciones sociales y económicas de subsistencia de las familias, en especial, de las urbanas.

3 La información expuesta en esta parte $-\mathrm{y}$ en los subsecuentes dos incisos- se fundamenta en los datos contenidos en la obra: Cambio demográfico y social en el México del siglo XX. Una perspectiva de historias de vida (2004); ello, en función de los estudios estadísticos realizados por los autores de la misma, entre los que destacan: Olivia Samuel, Pascual Sebille, Emilio Parrando, René Zenteno, Eric Janssen, Edith Pacheco, MarieLaure Coubès, y Carlos Javier Echarri Cánovas. 


\section{b) Mexicanos comprendidos en la Generación $X$, o bien, en la denominada mediática -según Krauze-, de la segunda mitad del siglo XX hasta aproximadamente 1980:}

Pese a las políticas implementadas en las primeras décadas del siglo XX, se advierte un considerable estancamiento del nivel educativo en jóvenes mexicanos de las zonas rurales, respecto del que ya tenían los jóvenes con residencia urbana para los años treinta.

También se sigue observando un descenso continuo y progresivo de los índices de mortalidad; pero también comienza a disminuir la fecundidad en los mexicanos a partir de finales de los años setenta, derivado de las políticas públicas e implementación de programas de anticoncepción y control de la natalidad a través del uso de anticonceptivos.

La población es mayoritariamente urbana (incremento del fenómeno social de migración interna, del campo hacia la ciudad).

La inserción de las mujeres al mercado de trabajo asalariado, el hecho de que la industria se volviese uno de los motores más importantes de crecimiento, la intervención del Estado en los sectores de producción, entre otros factores, significó durante la segunda mitad del siglo XX en México, hacia la década de los sesenta hasta finales de los setenta, un avance socioeconómico con oportunidades de empleos más productivos y mejor pagados, destacándose esta circunstancia en las zonas urbanas, en donde las familias se conformaban con un proveedor único. Para este tiempo, los mexicanos de las zonas rurales se dedicaban a la producción de materias primas para la industria, así como a la producción de alimentos (mucho para autoconsumo de las familias).

De igual manera, durante este periodo, inicia una tendencia de diferencia ocupacional entre padres e hijos, desplazándose estos últimos a un modelo ocupacional urbano. En el caso rural, esa diferencia ocupacional se fue haciendo más grande de una manera paulatina.

Hay una expansión del sistema educativo. La vida en familia se alarga gracias al descenso de la mortalidad en los padres (Coubès y otros, 2004). 


\section{c) Rasgos sociológicos en los que se desarrollan los mexicanos Millennials (nacidos entre 1980 hasta 1995, hijos y nietos de los veteranos del 68) desde su surgimiento, hasta la actualidad:}

Para principios de la década de los ochenta en México, se comienzan a sentir en la sociedad los efectos de la crisis económica en la que se ve inmerso el país en estos años. Ello sucede en todos los sectores sociales de las familias mexicanas en las que viven niños Millennials que nacen a partir de esta época. La mortalidad desciende significativamente. De igual forma, disminuye la fecundidad, por el uso continuo de anticonceptivos y la planificación familiar. Para finales de los años noventa, se advierte la predominancia de matrimonios civiles y religiosos, derivado de la tradición que se venía desarrollando desde inicios de siglo (Coubès y otros, 2004); sin embargo, también se observa un relativo incremento de las uniones libres, lo que va en ascenso con el pasar de los años hasta la actualidad, convirtiéndose en un rasgo peculiar de los Millennials de la segunda década del siglo XXI.

Igualmente, desde finales de los noventa, se da una mayor aceptación social de modelos alternativos de familia (las rupturas matrimoniales por separación incrementan, y hay más madres solteras por convicción propia), sin que para esas fechas se advierta una aceptación de matrimonios y uniones no convencionales, como las homosexuales, las cuales, han sido objeto de discusión social (con trascendencia constitucional y legal, tomando como referente el rumbo jurídico internacional) hasta el transcurso de la segunda década del siglo XXI en México. También, respecto del modelo tradicional de matrimonio, se advierte estabilidad, la que es mayor en la zona urbana que en la rural.

Hay una recomposición del papel de la mujer en la sociedad, que, si bien ya comenzaba a darse desde las primeras décadas de la segunda mitad del siglo XX, lo cierto es, que para el tiempo en que se desarrollan los Millennials mexicanos, las mujeres cuentan con un mayor acceso al sistema educativo, utilizan a menudo métodos de anticoncepción, y participan más en los sectores laborales en los que tradicionalmente se encontraban más involucrados los hombres. Esta recomposición obedece, en parte, a un impulso generado por el aparato estatal mexicano, emanado del ánimo de estar a la par de la tendencia internacional en 
pro de los derechos humanos, y en concreto, de las mujeres.

El trabajo de la tierra ya no es tan relevante como en la primera mitad del siglo XX (incluso, los mexicanos Millennials de zonas rurales se caracterizan por emigrar constantemente a los Estados Unidos de América, dejando los campos solos). De hecho, a partir de los noventa, comienza a darse una reestructuración política y social del campo mexicano, que ante la falta de producción, da por concluido el reparto agrario, y pretende proporcionar seguridad jurídica a los campesinos, respecto a la tenencia de la tierra facultándoles para decidir sobre el aprovechamiento de sus recursos productivos (Carmona, 1992).

Los hijos ya no necesariamente se quieren dedicar a lo mismo que sus padres. Lo que significa una mayor brecha en la diferencia ocupacional de hijos frente a padres en México (Coubès y otros, 2004).

Sin embargo, pese a los avances sociales significativos y las políticas públicas que los pretenden impulsar, actualmente existen condiciones sociológicas no tan favorecedores para el modus vivendi de esta generación de mexicanos, tales como las que se detallan enseguida:

Un mercado laboral inestable (aunque flexible) a raíz de las políticas de industrialización y liberalismo económico de los últimos treinta años (panorama que pudiese empeorar ahora, con el triunfo de Donald Trump como Presidente de los Estados Unidos de América -2016-, y su pretensión de replantear el Tratado de Libre Comercio de América del Norte con México y Canadá, así como su promesa de campaña, de deportación de mexicanos); la eliminación de protecciones laborales (sistema de pensiones en quiebra; ausencia de fuentes formales de empleo; y el incumplimiento de la legislación laboral y en materia de seguridad social, por las empresas privadas y el mismo Estado, como patrón en el sector público y burócrata; tan sólo por mencionar algunos problemas latentes en este sentido); el incremento del empleo informal (mayor autoempleo -aquí se incluye el llamado freelance de los Millennials-, o bien, el empleo en pequeñas empresas no consolidadas y con dificultades de subsistencia); la subida descomunal del dólar frente al peso mexicano, de los combustibles y de los productos de la canasta básica, entre otros.

Todo lo anterior, forma parte de la gama de obstáculos que tiene que enfrentar el Millennial mexicano de hoy en día. 


\section{Líneas programáticas de corte social contempladas en el constitucionalismo mexicano del siglo $\mathrm{XX}$}

Al efecto, es menester tomar como base del constitucionalismo mexicano del siglo XX, a la Constitución Política los Estados Unidos Mexicanos promulgada en el año 1917. Durante la discusión del proyecto de la citada Constitución, se plantearon las siguientes líneas programáticas en el ámbito de los derechos de libertad de las personas (éstas se advierten del apartado constitucional dogmático, y acorde a los debates del Constituyente respectivo, los que iniciaron desde 1916), las cuales se pueden categorizar como de corte eminentemente social (Covarrubias, 2010: 577-627):

- Igualdad en el goce de los derechos de libertad (reconocimiento expreso de la población indígena), que para aquél entonces comenzaban a identificarse como garantías.

- Prohibición de la esclavitud.

- Educación primaria laica, gratuita y obligatoria.

- Derecho de elegir la profesión, industria, comercio o trabajo que mejor se acomode a cada individuo.

- Prohibición de trabajos personales, y la obligatoriedad de los servicios públicos.

- Libre manifestación de ideas.

- Libertad de imprenta.

- Derecho de petición.

- Derecho de asociación.

- Derecho de posesión de armas.

- Libertad de tránsito.

- No concesión de títulos nobiliarios.

- Derecho a no ser juzgado por leyes privativas ni por tribunales especiales.

- No irretroactividad de la ley.

- Reglas para la extradición, y establecimiento de garantías de seguridad jurídica. 
- Fundamentos para la administración de justicia.

- La organización del sistema penal (en un primer dictamen respecto del proyecto constitucional, se discutió la base de un sistema inquisitorio con reservas -planteadas durante los debates del Constituyente de 1916- tales como: el sustituir la pena de privación de la libertad cuando hubiese la posibilidad de establecer penas alternativas, por ejemplo). La detención del acusado, la imposición de penas, las penas que quedarían prohibidas (en los debates se discutieron tópicos cruciales, como la pena de muerte). Instancias de conocimiento de los juicios criminales.

- Libertad de creencia religiosa.

- Circulación de correspondencia.

- Derechos de los miembros del ejército en tiempos de guerra.

- Derecho de propiedad y modalidades de posesión de la tierra.

- Prohibición de los monopolios y promoción de la libre concurrencia en la producción industrial, comercial o de servicio público.

- Supuestos para la suspensión de garantías.

- Prerrogativas de los ciudadanos mexicanos (derechos político-electorales, mismos que para 1917 no se otorgaron a las mujeres).

\section{Los Millennials mexicanos en el siglo XXI. ¿Decadencia del constitucionalismo programático de post revolución?}

Siguiendo nuevamente a Krauze (2016), los Millennials de este país son: “(...) ubicuos, originales, impetuosos e inconfundibles. Son la Generación internética por excelencia. La del Facebook, Twitter, Instagram y tantos otros medios de vertiginosa interacción. Grandes empresas quieren conocerlos para canalizar sus productos. Grandes escritores buscan descifrarlos para vislumbrar el futuro (...) (...) Se necesita su participación para dar sustancia a la democracia y construir el Estado de derecho que hace falta (...) (...) Tampoco participan firmando solicitudes, protestas, manifiestos. Son libres pero tienden a usar su libertad en las redes sociales (que, paradójicamente, sólo un 27\% considera útiles 
como instrumento de participación política). Su crítica en redes sociales rebosa indignación, energía, imaginación visual y humor. También fugacidad. La multitudinaria protesta virtual es alentadora, pero una democracia funcional requiere incidencia concreta en la realidad institucional. Ni modo: alguien tiene que ocuparse de los mundanos problemas prácticos de la sociedad.

Según varias encuestas, la falta de participación revela el desinterés de los Millennials en la política. ¿Por qué? Porque los políticos son deshonestos, porque actuar en política es inútil, porque no entienden de política (...)

(...) jóvenes con algún ideal más allá del dinero y el alcohol. Algunos practican la crítica en medios alternativos. Sus opiniones son frescas, irreverentes, no ideológicas. Otros encabezan iniciativas cívicas, fundaciones de filantropía y ONG dedicadas a defender los derechos humanos. El medio ambiente es un tema que les preocupa seriamente (...)

¿Qué los limita? Desde luego, las absurdas y alevosas barreras que impone la legislación actual: un número ridículamente alto de afiliados y asambleas en cada estado. O la dificultad de encontrar un empleo. O un nihilismo de fin del mundo. Les preocupa el calentamiento global, el terrorismo, las migraciones, la desigualdad rampante entre billonarios y pobres, la extinción de las especies. En una palabra, la destrucción del planeta. Todo lo cual se entiende, pero el planeta no se acabará en el tiempo de sus vidas. El tiempo los alcanzará, tarde o temprano. ¿Y quién gobernará en México entonces? (...)”

La generación de los Millennials, hablando en términos generales, es decir, sin pretender categorizar según la nacionalidad de los individuos que la integran, se refiere a personas con las siguientes características: creativas e innovadoras; pretenden ser originales; más que espectadores quieren ser partícipes del contexto en el que se encuentran; son visuales (homo videns ${ }^{4}$ ), tecnológicos, y se desenvuelven en redes sociales del ciberespacio; cuestionan las políticas públicas y los programas de gobierno; son irreverentes (y en veces, por ello mismo, suelen incurrir en la intolerancia; aunque pugnan por el respeto a los derechos de libertad, lo que puede llegar a ser socialmente contradictorio); quieren modelos educativos efectivos y a distancia; saber más de un idioma; y a menudo suelen utilizar

\footnotetext{
4 Incluso, este término es acuñado por Giovanni Sartori (2010:165), en su obra Ingeniería constitucional comparada (traducción de Roberto Reyes Mazzoni, $3^{\circ}$ ed., cuarta reimpresión). México: Fondo de Cultura Económica.
} 
términos tecnológicos y anglosajones en su vocabulario para autodenominarse e identificarse del resto de la sociedad (son los llamados whistleblowers, hackers, freelancers, geeks, nerds, o hipsters). Éstas son algunas de sus características.

En definitiva, si pretendemos definir a los Millennials mexicanos, nos encontraremos con individuos totalmente distintos a aquéllos revolucionarios de principios del siglo XX. Son diferentes también a aquellos mexicanos de mitad del siglo pasado, que fueron partícipes de movimientos anti sistémicos como el de 1968. Son hijos y nietos de estos últimos, pero con ideales de vida diversos en todos los sentidos.

Otro dato importante, es que la generación de los Millennials comprende tanto a personas que viven en zonas urbanas, como a las que habitan en las rurales, lo cuales, con independencia de las trabas que se les presentan para acceder a recursos tecnológicos, es innegable el hecho de que han nacido en la era de los avances científicos más significativos (Rodríguez Jaramillo, 2016):

“(...) las tecnologías de la información y las comunicaciones nos enfrentan a la lógica de la simultaneidad que conlleva a una ruptura de tiempo y espacio que tiene el potencial de romper la división entre lo urbano y lo rural, redefiniendo las brechas entre estos dos mundos. Hoy se acepta que las brechas se relacionan más con la forma en que las personas acceden y se apropian de las tecnologías y menos con el lugar que habitan, lo cual democratiza las oportunidades y permite que los jóvenes sean Millennials en el campo y la ciudad".

¿Qué quieren los Millennials? Quieren, entre muchas otras cosas: justicia y paz social; que se garantice materialmente y en todos los ámbitos -incluido el espacio virtual de la información- la libertad de expresión; el libre tránsito, no sólo terrenal, sino también cibernético; medios que garanticen un verdadero acceso a la información pública; privacidad en su espacio físico y virtual; autoridades que den el ejemplo con el cumplimiento de los mandatos constitucionales y legales, es decir, que sean éstas las primeras en cumplir y hacer cumplir las leyes; mejores oportunidades de empleo en trabajos no tradicionales y con ambientes tampoco convencionales y con flexibilidad de horarios; quieren líderes, no quieren jefes (no sólo laboralmente hablando, sino también refiriéndose a los futuros jefes de Estado y de Gobierno); equidad de género; inclusión de minorías; sustentabilidad 
ambiental y económica; menos barreras burocráticas y normativas que les dificulten poder ser emprendedores de negocios; quieren viajar y tener tiempo para el deporte y otras actividades de ocio.

Demandan tanto, que el Estado -y por supuesto que hablamos del Estado Mexicano- se puede quedar corto. De hecho, hay quienes han criticado a esta generación, y han llamado a cierto sector de éstos como idiotas empoderados, en tanto que es la nueva clase de personas que está decidiendo el rumbo y determinando el surgimiento de situaciones inauditas, como por ejemplo, que en el Reino Unido la mayoría de la población haya elegido salir de la Unión Europea, o que en Colombia, la mayoría -en un primer momento- hubiese rechazado que el gobierno firmara la paz con las FARC (Carrillo Hernández, 2016).

En el caso concreto, es decir, por lo que toca al objeto a estudio, relativo al constitucionalismo mexicano con relación a la generación de los Millennials, se considera que la Carta Magna mexicana, a 100 años de su promulgación desde 1917, y la legislación secundaria -por consecuencia-, se encuentran en peligro de quedarse cortas, y resultar insuficientes a la cantidad enorme de nuevos requerimientos sociales. Están en peligro inminente de convertirse en meros instructivos de aparatos electrodomésticos descontinuados, porque las líneas programáticas de la Constitución de 1917, mismas que repercuten en el diseño de la legislación secundaria del sistema jurídico, no han sido sujetas a una verdadera, cabal y exhaustiva revisión respecto del cambio social que ha venido experimentando el país desde la segunda mitad del siglo pasado.

Las modificaciones del texto constitucional $-y$ por ende, de la normativa secundaria-, en los últimos años, pareciera que obedecen más a clientelismos, a intereses particulares de agentes políticos y de autoridades corruptas.

Si bien se observa que las líneas programáticas de corte social establecidas en la Constitución de 1917, incluyeron tópicos de interés colectivo en cuanto a la inclusión -desde una perspectiva deontológica generalizada- de derechos básicos como el de educación, el de libertad de trabajo, de libertad de expresión, el de propiedad con modalidades en la posesión de la tierra, la libertad de credo religioso, entre otros derechos que ya han sido señalados en la parte correspondiente de este trabajo, lo cierto es, que el contexto en el que han ido evolucionando dichos tópicos ha cambiado considerablemente, en gran medida, derivado de los avances 
tecnológicos que han dado pauto al fenómeno de globalización, y que han incidido sin lugar a dudas en nuestro país, no sólo en el ámbito cultural, sino también en el económico, político, y, por supuesto, en el jurídico.

Y aún y cuando el texto original de la constitución de 1917 ha sido modificado a través de numerosas reformas constitucionales -el sitio oficial de la Cámara de Diputados del Congreso de la Unión (2017) arroja un dato numérico y en orden cronológico de 231 decretos de reforma constitucional, publicados en el Diario Oficial de la Federación, al 24 de febrero de 2017-, no se puede dejar de lado que las demandas sociales de los Millennials continúan siendo, en gran medida, agenda pendiente del constitucionalismo mexicano actual. Algunas de estas demandas ya han sido detalladas con anterioridad, apuntando, en este momento de la argumentación, sobre todo a los siguientes puntos: La libertad de expresión en el espacio virtual de la información; mejores oportunidades de empleo en trabajos no tradicionales y con ambientes tampoco convencionales; equidad de género y la inclusión de minorías y grupos vulnerables como aquellos que tienen que ver con la discrepancia entre identidad de género y la identidad sexual; sustentabilidad ambiental y económica; disminución de barreras burocráticas y normativas que dificulten el emprendimiento de negocios y la regulación de monedas virtuales diversas a la moneda nacional emitida por el organismo constitucional autónomo descrito en el ordenamiento supremo; etcétera.

Sin embargo, no todo está perdido. Las nuevas perspectivas de justicia constitucional -como se expondrá en el siguiente apartado-, así como futuros y nuevos retos para el texto normativo supremo mexicano, en el campo de la interpretación constitucional y legal, pueden dar pauta a una reinvención del sistema jurídico, a fin de que éste sea ad hoc a la sociedad actual:

“(...) La Generación de los Millennials no podrá permanecer on hold. La adolescencia no puede prolongarse indefinidamente. Los más jóvenes tienen 20 años, los mayores 35. Son extraordinariamente inventivos. Ojalá retomen la construcción de la casa en obra negra (injusta, violenta, impune) que les heredamos" (Krauze, 2016). 


\section{El surgimiento de nuevas perspectivas de justicia constitucionalcomoavancesignificativo delconstitucionalismo mexicano en la era de los Millennials}

Entre el orden constitucional y el modo de ser y querer ser de un pueblo, tiene que existir una adecuación; la misma es indispensable para que la Constitución adquiera una vigencia real y efectiva, conservando al mismo tiempo su vigor jurídico-formal (Molina Ramos, 2013:80).

Un constitucionalismo moderno supone dos elementos clave en los que el Estado debe poner especial hincapié: primero, el respeto de los derechos humanos (o mejor dicho fundamentales, cuando ya han sido constitucionalizados); $\mathrm{y}$ segundo, la existencia de mecanismos idóneos para su protección, que es lo mismo que hablar de un sistema de justicia constitucional compuesto de medios de control efectivos y eficaces, en el entendido de que esta tipología de derechos fundamentales es lo que da verdadera sustancia a un ordenamiento supremo que se jacte de ser democrático.

México ha incursionado, desde luego, en la búsqueda de nuevas perspectivas de justicia constitucional.

Hasta finales del año 2011, el sistema jurídico mexicano había reconocido de manera única y exclusiva, la competencia de la Suprema Corte de Justicia de la Nación, como órgano jurisdiccional de mayor jerarquía, para conocer del control de la constitucionalidad (control concentrado) en aquellos supuestos donde se contravenía el ordenamiento supremo por la aplicación de una determinada normativa contraria a la Constitución. A excepción de la materia electoral, en lo referente al artículo 99 constitucional (reformado en 2007), en que se otorga la facultad al Tribunal Electoral del Poder Judicial de la Federación para inaplicar normas contrarias a la Carta Magna, el control constitucional en México se encontraba bastante limitado.

Sin menospreciar los esfuerzos realizados desde 2007, que en materia electoral, permitieron la entrada de un control difuso de constitucionalidad, el sistema jurídico mexicano comenzó realmente a ocuparse de la búsqueda de nuevas perspectivas de justicia constitucional a partir del año 2011, cuando 
logró la aceptación de una nueva reinterpretación del artículo 133 constitucional, surgiendo las primeras tesis que establecen las reglas para que los operadores jurídicos del país realicen el control concreto o difuso de la constitucionalidad en todas las materias, sobre la base de proporcionar las condiciones más favorables a las personas. Así nació un nuevo modelo de justicia constitucional en México, que es el que opera hoy en día, de control mixto; es decir, no monopolizado por la Suprema Corte de Justicia de la Nación, como se venía dando durante todo el tiempo que precedió la última fecha mencionada (2011).

No queda duda que lo anteriormente señalado, al decretarse vía jurisprudencial a finales de 2011 -y al seguirse desarrollando un bagaje teórico amplio a la fecha-, significa un avance constitucional fundamental surgido precisamente en la era de los Millennials. Y lo más importante, es que ese cambio paradigmático fue producto de la interpretación de la Constitución, en tanto que ésta fue tomada en serio; es decir, que más allá de considerarla como mero texto instructivo de órdenes y mandatos, fue considerada como un instrumento real, contenido de valores y principios por los que vivimos e interactuamos como sociedad democrática actual.

\section{Conclusiones}

Una primera conclusión de este trabajo de investigación, lo es el afirmar que los mexicanos activos social, económica, cultural y políticamente en el presente contexto (adultos jóvenes Millennials y sus descendientes generacionales), han cambiado; que no poseen los mismos ideales de vida, aspiraciones y modus vivendi de las generaciones que les precedieron y que, en su momento, dieron pauta también a transformaciones importantes, como aquéllas derivadas de revoluciones armadas que sacudieron paradigmáticamente al Estado Mexicano, (de hecho, la misma Constitución de 1917 y su contenido programático social son producto de ello, si nos remontamos a la Revolución Mexicana de 1910, por señalar un caso significativo del constitucionalismo mexicano contemporáneo).

El planteamiento de una segunda conclusión, lo constituye el afirmar que, 
al verificarse el hecho de que los mexicanos activos hoy en día (una gran parte de ellos son Millennials, lo que se corrobora con el lapso generacional que fue detallado en este trabajo) son totalmente distintos a aquéllos revolucionarios de principios del siglo XX, y diferentes también a aquellos mexicanos de mitad del siglo aludido (que fueron partícipes de movimientos anti sistémicos como el de 1968, por ejemplo), existe decadencia del constitucionalismo mexicano.

Consecuentemente, deviene una decadencia de todo el sistema jurídico de este país. Sin embargo, ésta puede ser enfrentada mediante alternativas de solución que para nada están relacionadas con una inflación desproporcionada de tipo legislativo o, incluso, de reformas constitucionales; sino que se proponen aquéllas que se encuentran en el campo de la interpretación constitucional y legal, en armonía a los principios fundamentales que se encuentran reconocidos en el propio texto constitucional vigente, como el de progresividad y el pro homine. Al respecto, tal y como se expuso en el último apartado de este trabajo, destaca en el constitucionalismo mexicano el avance significativo logrado a partir del año 2011 -vía jurisprudencial-, en materia de justicia constitucional, que dio pauta a una concatenación del control concentrado de constitucionalidad operado de forma exclusiva por la Suprema Corte de Justicia de la Nación, con el control difuso realizado por los demás operadores del sistema jurídico mexicano.

\section{Bibliografía}

Browning, H., Coubès, M., Echarri, C., Janssen, E., Mier, M., Pacheco, E., Parrando, E., Samuel, O., Sebille, P., y otros (2004). Cambio demográfico y social en el México del siglo XX. Una perspectiva de historias de vida. México: Edición del Colegio de la Frontera Norte y otros. Recuperado el 7 de noviembre, 2016, de: http://biblioteca. diputados.gob.mx/janium/bv/ce/scpd/LIX/cam dem soc mex.pdf

Camacho,C.(2015). Prólogo. México: memoriayfuturo. CONSTITUCIÓN DE 1917. 100 años de vigencia, estabilidad y evolución (edición de Rodolfo Echeverría y Carlos González Manterola). Recuperado el 3 de noviembre, 2016, de: https://issuu.com/espejodeobsidiana/docs/ mexico memoria y futuro 
Carmona Dávila, D. (1992). Se termina la reforma agraria y se abre el campo al capital mediante la reforma al artículo 27 de la Constitución. Memoria Política de México (6 de enero de 1992). Recuperado el 4 de noviembre, 2016, de: http://www.memoriapoliticademexico.org/ Efemerides/1/06011992.html

Carrillo Hernández, J. (2016). Idiotas empoderados: La nueva clase que está decidiendo el futuro de la humanidad. PIJAMASURF (11 de septiembre de 2016). Recuperado el 3 de diciembre, 2016, de: http:// pijamasurf.com/2016/11/idiotas_empoderados_la_nueva_clase que esta decidiendo el futuro de la humanidad/

Covarrubias Dueñas (2010). El paradigma de la Constitución (México 1917-2010). México: Porrúa.

Krauze, E. (2016). El misterio de los millennials. EK PERSONAS E IDEAS, PORTAL DE ENRIQUE KRAUZE (5 de junio de 2016). Recuperado el 3 de noviembre, 2016, de: http://www.enriquekrauze. com.mx/joomla/index.php/opinion/97-art-critica-social/976-elmisterio-de-los-millennials.html

Molina Ramos, M. (2013). Análisis del artículo 133 constitucional. Tesis de grado de Maestría en Derecho Público (asesor M.D.P. Raúl A. Villarreal de la Garza). Nuevo León, México: División de Estudios de Posgrado de la Facultad de Derecho y Criminología, Universidad Autónoma de Nuevo León. Recuperado el 4 de noviembre, 2016, de: http://eprints.uanl.mx/5277/1/1020148595.PDF

Lazcano-Ponce, E. y otros (2000). Estudios de cohorte. Metodología, sesgos y aplicación. Revista Salud Pública de México, Volumen 42 (edición del Instituto Nacional de Salud Pública, Número 3, mayo-junio de 2000). Recuperado el 7 de noviembre, 2016, de: $\quad$ http://www.scielosp.org/scielo.php?script $=$ sci arttext\&pid $=\mathrm{S} 0036-36342000000300010$

López Guerra, L. (2013). Derecho Constitucional. Volumen I. El ordenamiento constitucional. Derechos y deberes de los ciudadanos. Valencia: Tirant Lo Blanch.

Rodríguez Jaramillo, A. (2016). Millennials rurales serán portadores 
del cambio. NAO CLÚSTER (20 de mayo de 2016). Recuperado el 3 de diciembre, 2016, de: http://www.naocluster.com/2016/05/ millennials-rurales-seran-portadores.html

Sáchica, L. (2002). Constitucionalismo mestizo. México: Universidad Autónoma de México.

Sanz, E. (2014). ¿Cómo son los miembros de la Generación X? Revista Muy Interesante. Recuperado de 5 de noviembre, 2016, de: http:// www.muyinteresante.es/salud/articulo/icomo-son-los-miembros-dela-generacion-x

Sartori, G. (2010). Ingeniería constitucional comparada (traducción de Roberto Reyes Mazzoni, $3^{\circ}$ ed., cuarta reimpresión). México: Editorial Fondo de Cultura Económica.

Consulta realizada el 28 de agosto de 2017 en: http://www.diputados. gob.mx/LeyesBiblio/ref/cpeum_crono.htm 
